\title{
BIO-FIBRE EARTH COMPOSITE MORTAR: A STRUCTURAL AND HYGROTHERMAL ASSESSMENT
}

\author{
Abbie Romano ${ }^{1}$, Ana Bras $^{1 *}$, Sotirios Grammatikos ${ }^{2}$, Andy Shaw $^{1}$ and Mike Riley ${ }^{1}$ \\ ${ }^{1}$ Built Environment and Sustainable Technologies (BEST) Research Institute, Department of \\ Built Environment, Liverpool John Moores University, Byrom Street, Liverpool, L3 3AF, \\ UK \\ ${ }^{2}$ Department of Manufacturing and Civil Engineering, Norwegian University of Science and \\ Technology, 2815 Gjøvik, Norway \\ *Corresponding author; e-mail: a.m.armadabras@ljmu.ac.uk
}

\begin{abstract}
Bio-fibres and earth as a building material have been used for thousands of years and can be utilised due to their relative abundancy around the globe. The aim of this work is to combine these materials in order to give potential for a new, sustainably sourced, non-load bearing hygric buffering panel for indoor thermal management with bio-fibres commercialised in UK. Currently, there is limited knowledge specifically as to how bio-fibres and earth combine in order to enhance their inherent characteristics. This uses two differing mix designs and 3 differing bio-fibres (Wool 1, Wool 2 and Saw Mill Residue). Earth was utilised by using locally sourced material from Liverpool (NW England). Prismatic, $0.1 \mathrm{~m}^{2} \times 0.1 \mathrm{~m}^{2}$ and $40 \mathrm{~mm}$ disc samples were cast and samples were exposed to cyclical step changes in relative humidity at $75 \%$ for 8 hours and $53 \%$ for 16 hours at $23^{\circ} \mathrm{C}$, in order to mimic a UK household occupancy. Results demonstrate that an optimised mix lead to at least $30 \%$ improvement of properties if Saw Mill Residue (SMR) is added. In comparison to a plain earth mortar, the addition of SMR reduces density, porosity and increases moisture buffering.
\end{abstract}

Keywords: earth-based; bio-based; moisture buffering; agro-wastes

\section{INTRODUCTION}

Existing for thousands of years, using earth as a construction material is not uncommon and has been fundamental for buildings around the world (Emiroğlu, Yalama and Erdoğdu, 2015) (Minke, 2006). These techniques have been left in the past in favour for more 'fashionable' and fossil fuel intensive materials such as steel and concrete. However, these materials are being rescinded due to environmental pressures and more sustainable construction techniques (such as utilising earth)are regaining importance (Aubert et al, 2015). Using earth as a building material is beneficial due to its low environmental impact (Chabriac et al, 2013) and as it is such an abundant material, it provides locally sourced material reducing carbon emissions associated with the transportation of materials (Cagnon et al, 2014; Asdrubali, D'Alessandro and Schiavoni, 2015). Furthermore, earth presents a high hygrospicity in addition to a low thermal conductivity, enabling it to locally regulate Relative Humidity (RH) 
RILEM's session 274-TCE: Testing and characterisation of earth-based building materials and elements

(Minke, 2006; Lima, Faria and Santos Silva, 2016). The ability to use earth as a part of an earth mortar contributes to its use as an extremely eco efficient and sustainable building material (Melià et al, 2014).

Despite this, earth-based construction has its disadvantages such as poor ductility and its hygroscopic shrinkage (Aymerich, Fenu and Meloni, 2012). Due to the level of exposure to earth-based construction, the durability of these buildings are low due to the earth's hydrophilic properties. In order to counteract this, a stabiliser must be used to further inherently improve structural strength and earth's resistance to water. Faria et al. (2013) investigated the behaviour of different binder content within an air-lime earth mortars, displaying increased thermal conductivity. Similar to previous research, Gomes et al. (2016) used both air-lime and hydraulic lime with varying weight of earth, increasing binder also increased water absorption coefficient. Further to the addition of earth and stabilisers, the incorporation of fibres to a mix design has been proven to be beneficial in terms of thermal characteristics by reducing thermal conductivity (Laborel-Préneron et al, 2016) and improving compressive strength (Palumbo et al, 2016).

Using the afore mentioned research, this paper will feature the use of hydraulic lime and biofibres in addition to earth. The overall aim of this paper is to develop and then select a biofibre earth mortar mix for use as a passive mechanism for building $\mathrm{RH}$ regulatory nonstructural panel. By investigating a locally sourced earth mortar bio-composite an appropriate mix design and bio-fibre will be selected.

\section{MATERIALS}

\section{Earth}

All of the earth used was collected from a construction site in central Liverpool (North-West England) from a depth of approximately $1.5-2 \mathrm{~m}$. Due to an abundance of construction waste materials, the earth was sieved at $2 \mathrm{~mm}$ to disregard any large pieces of aggregate and to ensure the creation of a homogenous material. In accordance with EN1015-1(CEN, 1999a) the earth was dry sieved and the grain size distribution is displayed for both earth and sand in Figure 1.

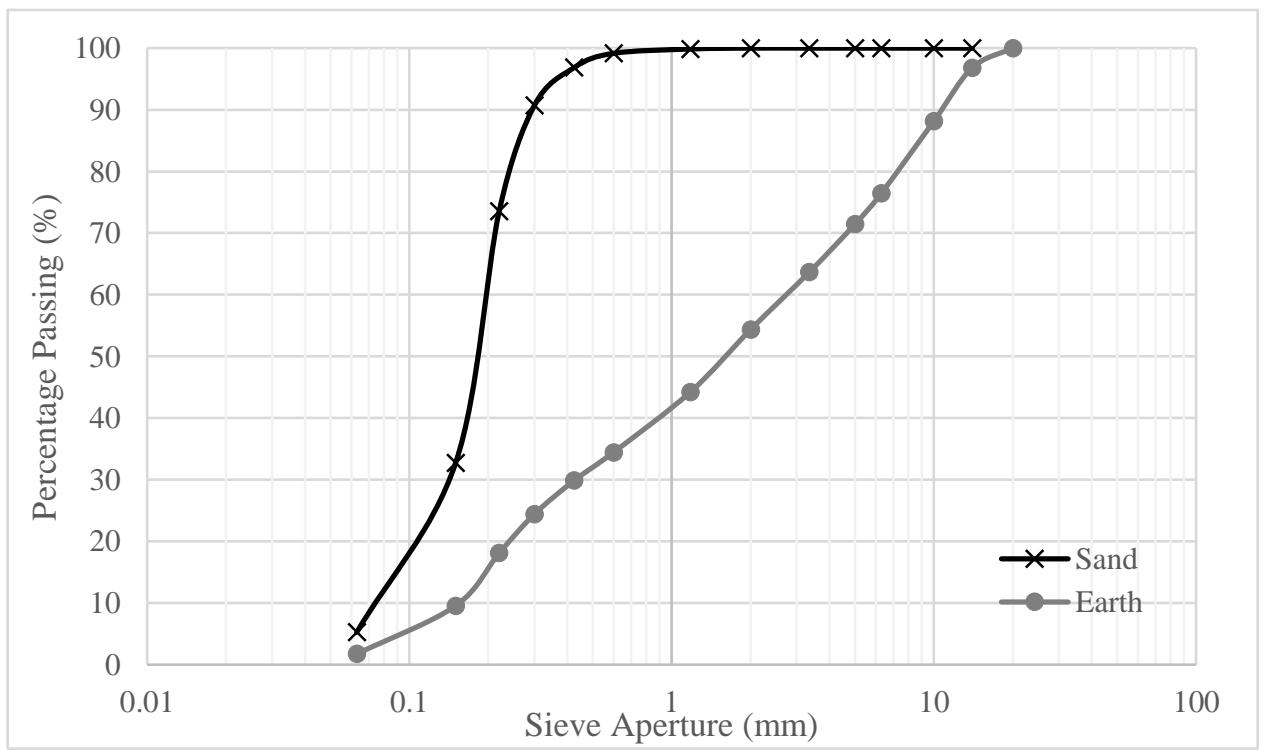


Figure 1. Grain size Distribution Chart.

\section{Bio-Fibres}

Three different types of bio-fibres were used within this research paper which are that of: Saw Mill Residue (SMR), Wool 1 (WL1), Wool 2 (WL2) and a non-bio-fibre sample (PL). All bio-fibres that were included are currently available on the market as bio-based insulation samples within the United Kingdom (UK).

\section{METHODS}

\section{Formulation}

All ingredients were formulated as per EN 1015-2(CEN, 1999b), where all dry ingredients (including bio-fibres) are mixed together to homogenise then water is added. Due to the fibrous nature of samples, fibres were pulled apart to avoid flocculation. To ensure all mixes were calibrated, water was added to the mix design to give a fixed consistence of 150-160 mm (using a flow table as per EN 1015-3 (CEN, 1999c). The mix design for Mix 1 and Mix 2 can be found in Table 1 . Prismatic (40mm x 40mm x 160mm), MBV square (100mm x $100 \mathrm{~mm} \times 35 \mathrm{~mm}$ ) and $40 \mathrm{~mm}$ disc samples were cast.

Table 1 - Mix design properties for Mix 1(M1) and Mix 2 (M2).

\begin{tabular}{|c|c|c|c|c|}
\hline $\begin{array}{c}\text { Mix } \\
\text { Design ID }\end{array}$ & Lime & Earth & Sand & Water \\
\hline M1 & 1 & 0.1 & 8.6 & 2.4 \\
\hline M2 & 1 & 0.3 & 10.3 & 2.7 \\
\hline
\end{tabular}

\section{Curing}

After 14 days, samples were demoulded and left to cure for a further 14 days (28 days total cure time) whilst also being elevated to ensure that all surfaces of the sample can dry simultaneously. Samples were cured in laboratory conditions of approximately $21^{\circ} \mathrm{C}$ and $54 \%$ RH.

\section{Experimental Procedure}

\section{Dry Bulk Density}

Using callipers to an accuracy of $0.01 \mathrm{~mm}$ and a $0.001 \mathrm{~g}$ balance dimensional readings were taken of prismatic samples in order to determine bulk dry density in accordance with EN 1015-10 (CEN, 1999d).

\section{Porosity}

As a method of calculating the void space within the sample, porosity gives an indication of how much water a substance can retain. Disc shaped samples of diameter $40 \mathrm{~mm}$ were cast, and the test method was performed as per EN 1936:2006(CEN, 2007). 
To demonstrate the capacity of a material to absorb in the short term, prismatic samples were partially submerged in accordance with EN 1015-18: 2002 (CEN, 2002).

\section{Moisture Buffering Value (MBV)}

In order to be able to adequately assess the ability of a material to adsorb and desorb water vapour from a local hygrothermal environmental a combination of NORDTEST protocol (Rode et al, 2005) and ISO 21453 (ISO, 2008). Samples were covered in aluminium tape, laid horizontally with an exposed surface area of $0.01 \mathrm{~m}^{2}$. After an initial stabilisation period of 24 hours at $23^{\circ} \mathrm{C}$ at $60 \% \mathrm{RH}$ samples were exposed to a cyclical step change in RH of $75 \%$ for 8 hours and 53\% for 16 hours (as per test conditions in (Romano et al, 2018)). MBV was calculated using Equation 1.

$$
M B V=\frac{m_{a}-m_{d}}{A \Delta \varphi}
$$

Where:

$\mathrm{m}_{\mathrm{a}}=$ Mass of sample at end of moisture adsorption stage $(\mathrm{g})$

$\mathrm{m}_{\mathrm{d}}=$ Mass of sample at end of moisture desorption stage $(\mathrm{g})$

$\mathrm{A}=$ Exposed surface area of sample $\left(\mathrm{m}^{2}\right)$

$\Delta \varphi=$ Difference in RH between adsorption and desorption stage (\%)

\section{RESULTS AND DISCUSSION}

\section{Dry Bulk Density}

For this research paper, the dry bulk density results for both mix designs are demonstrated within Figure 2. For MD1 dry bulk density values range from $1410-1707 \mathrm{~kg} / \mathrm{m}^{3}$ and $1575-$ $1615 \mathrm{~kg} / \mathrm{m}^{3}$ for MD2. By utilising the dimensional characteristics of each sample, it is clear from Figure 2 that the addition of bio-fibres reduces the dry bulk density for all samples from both mix designs. This is due to the fibres having a lower density than the PL mortar, which would usually occupy the same space as the fibres - these findings are in line with experimentation by (Gomes, Faria and Gonçalves, 2018). 
RILEM's session 274-TCE: Testing and characterisation of earth-based building materials and elements

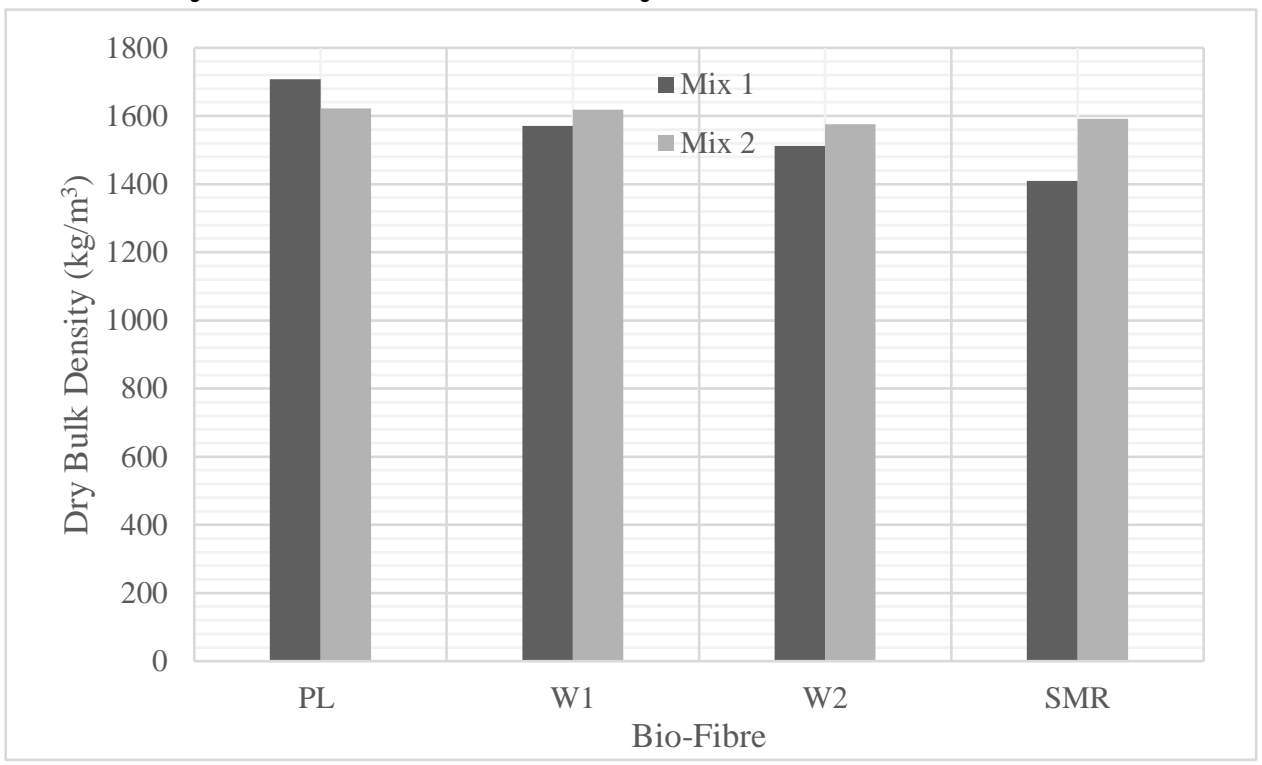

Figure 2. Dry Bulk Density of earth mortar samples.

\section{Porosity}

As a measure of the ratio of the quantity of open spaces which have the ability to be filled with a fluid within a materials microstructure, to the whole volume of the sample, open porosity gives an indication of the earth-based construction durability and resistance to deform. The results for open porosity can be found within Figure 3. With the exception of PL MD1, the addition of fibres increase porosity in all samples.

As porosity generally increases, by comparison dry bulk density decreases. Demonstrated within Figure 4, it is evident that dry bulk density has a moderately inversely proportional relationship (where Pearson Correlation Coefficient (PCC) $r=-0.65$ ) with open porosity. This relationship between porosity and dry bulk density and other material characteristics follows other research as explored in (Bouguerra et al, 1998) and (Laborel-Préneron et al, 2016).

In addition to this, the incorporation of lime into both mix designs and the cure time for these samples being only 28 days dictates that the lime is currently acting as a filler rather than a key structural element of the mix. As the carbonation process yet to occur within the mix, it has been evidenced the effect of carbonation on cement based mortars lowers the open porosity has been explored in (Lawrence et al, 2007) this process will also occur in earth based mortars. As a consequence of this, the open porosity values outlined in Figure 3 may reduce after a longer cure length where carbonation has taken place. 


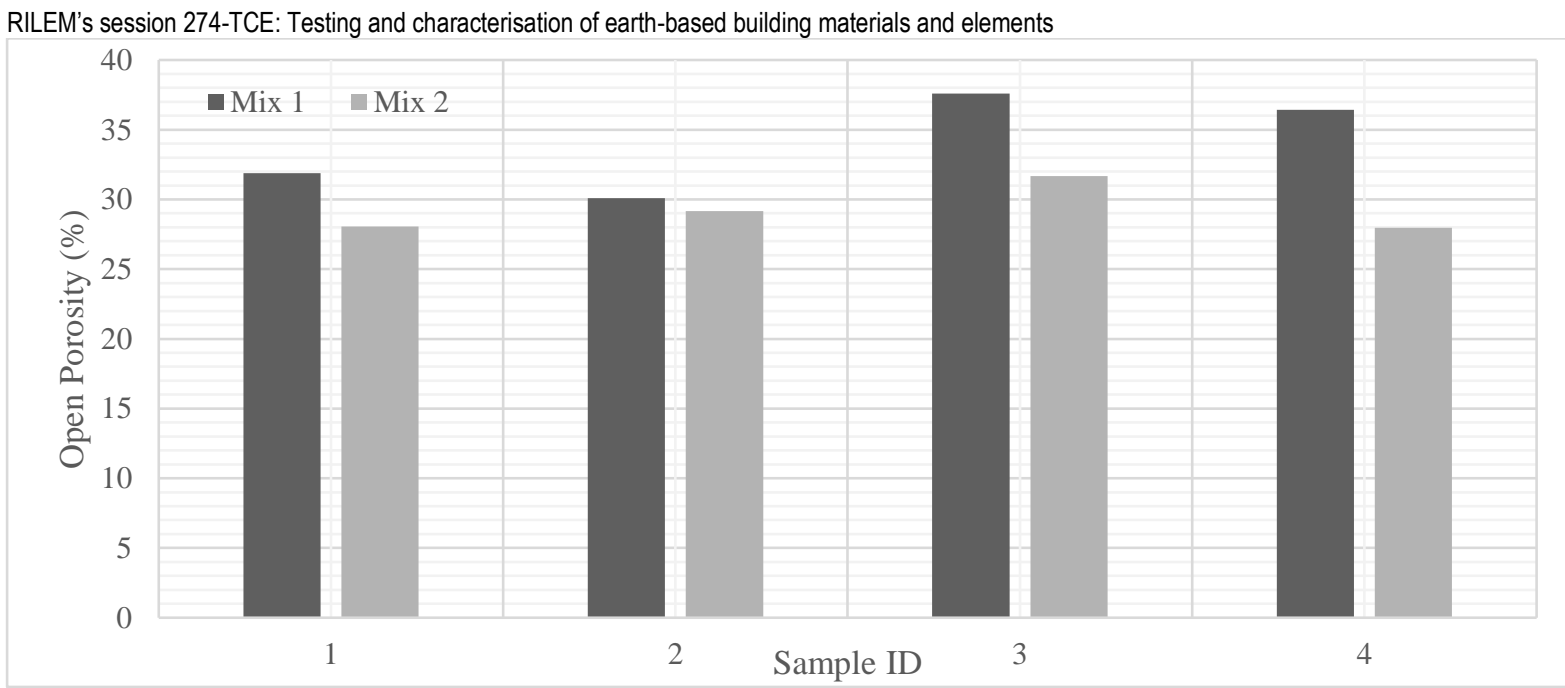

Figure 3. Open Porosity of earth mortar samples.

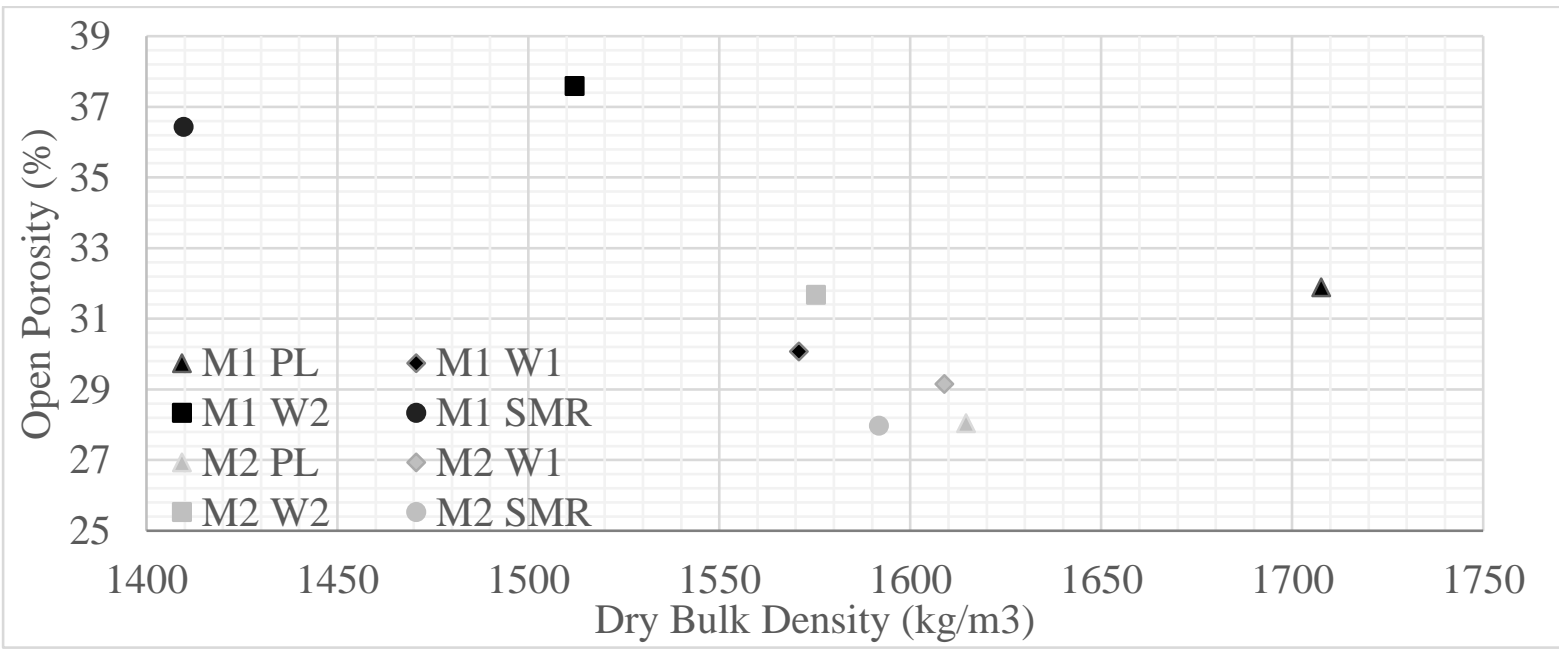

Figure 4. Relationship between open porosity and dry bulk density for earth mortar samples.

\section{Capillary Action}

As previously mentioned a key disadvantage of using earth based construction is its high deformation with exposure to water. Figure 5 demonstrates the capillary action curve for all samples. The initial water adsorption by a sample is greatest within M2 W1, which also continued to have the greatest over all stabilised water adsorption. By comparison, M1 PL had the smallest initial and constant water adsorption (plateau region). Concerning a mix design with bio-fibres, Mix 1 WL1 had the lowest initial water adsorption and then also the lowest, sustained water adsorption within the plateau region of Figure 5. All M1 samples have a lower initial and continual water adsorption in comparison to M2. Despite the aim of this paper to create a panel which will remain indoors, due to the low durability of earthen construction, the long-term absorption and its effect on service life must be considered. 
RILEM's session 274-TCE: Testing and characterisation of earth-based building materials and elements

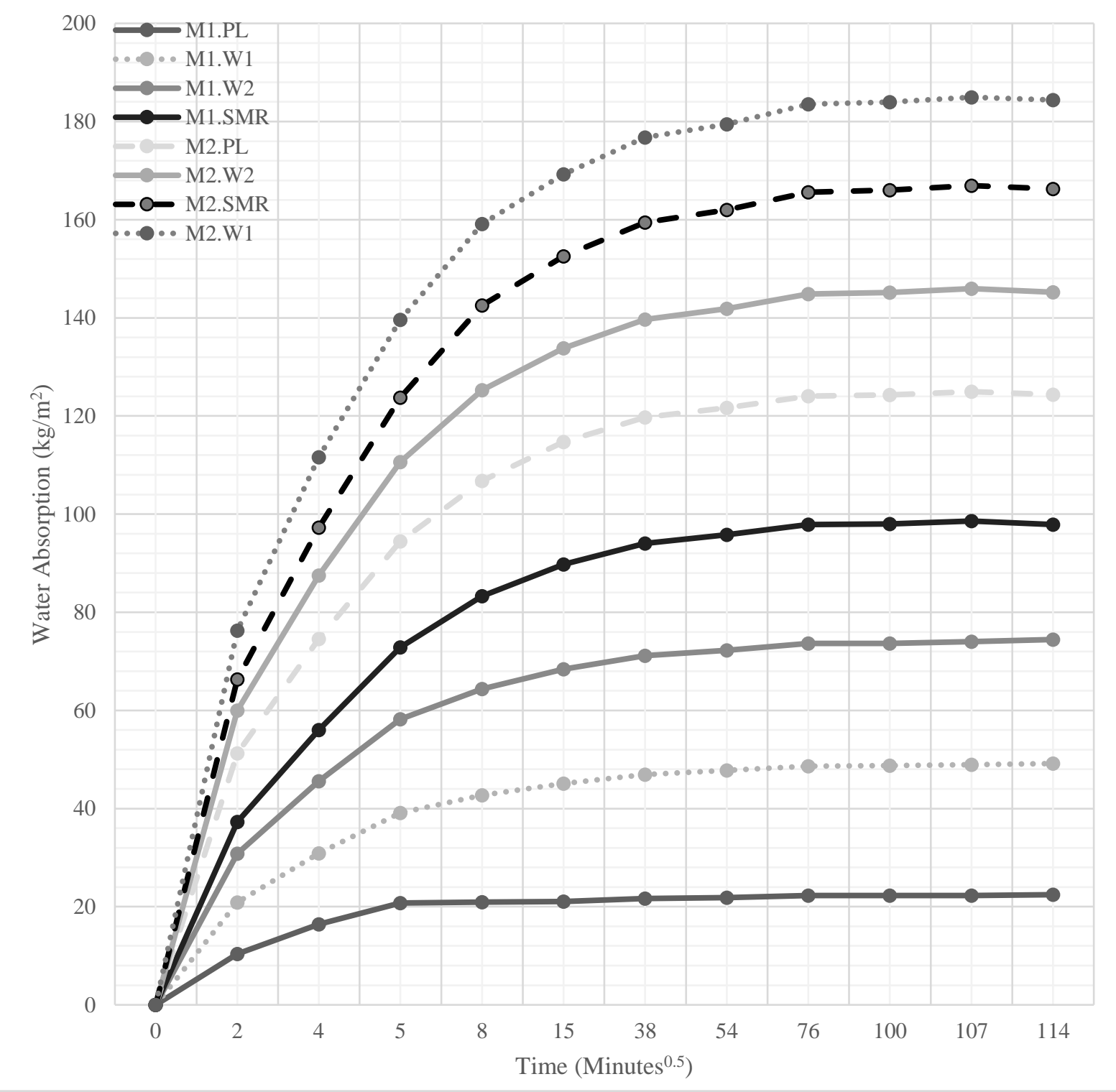

Figure 5. Capillary action curve for earth mortar samples.

\section{MBV}

To identify the way in which a sample efficiency and effectively exchanges water vapour is integral to this research as it identifies the moisture transport within each mix. All samples were exposed to 16 cycles of 24 hours, as outlined in (Romano et al, 2018) the MBV itself is not enough of a differentiation between samples that have similar or the same MBV.

Therefore, by having the same exposed surface area within the sample, the mass change graph per $\mathrm{m}^{2}$ can be utilised to demonstrate the mass variation for each cycle. The mass change graph for cycle 15 is presented within Figure 6. 


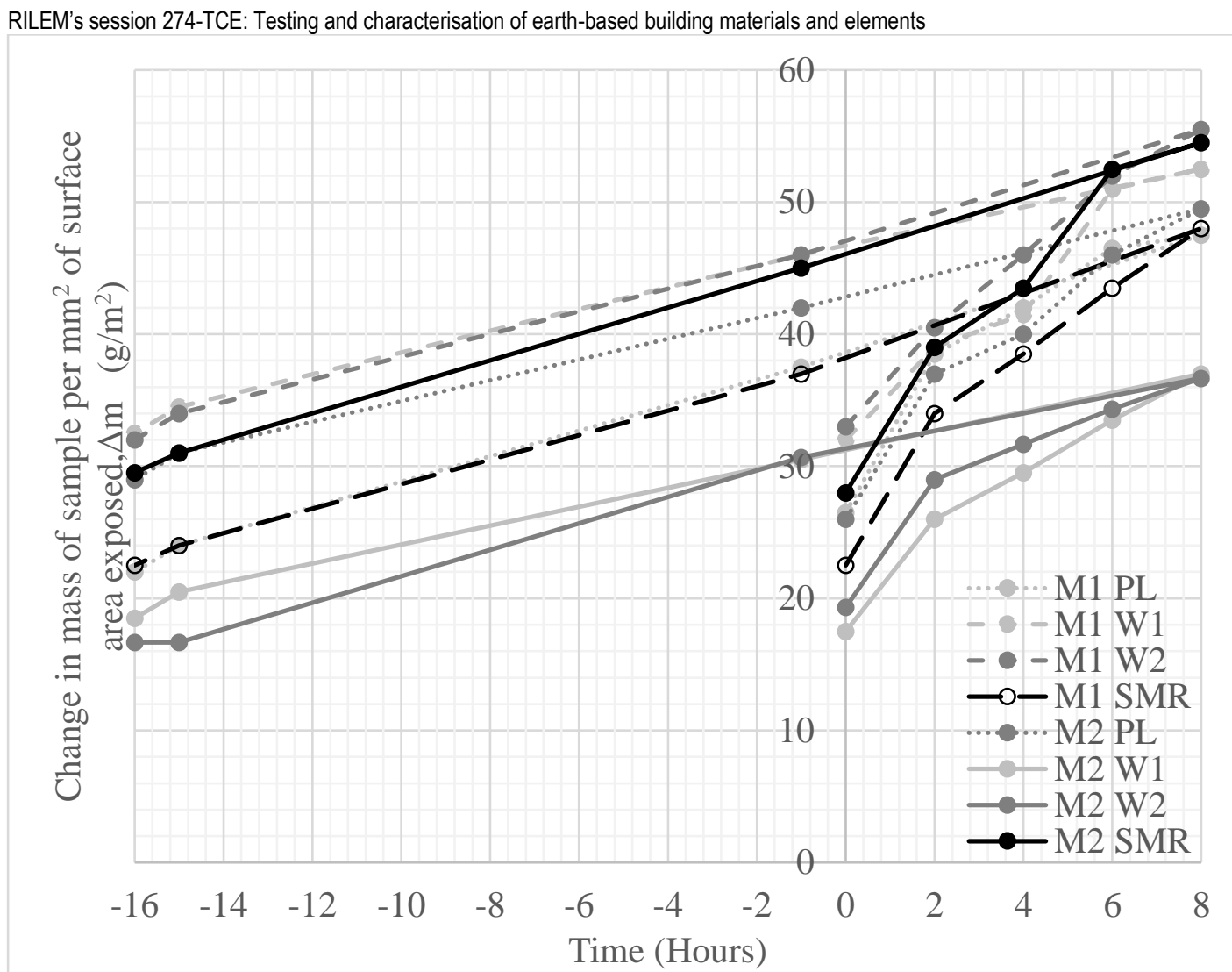

Figure 6. Adsorption/Desorption graph for all earth mortar samples after 14 cycles of 24 hour each.

After 14, 24 hour cycles it is evident that all mix designs have not remained at their original mass. All samples have increased in mass, this is sufficient evidence to suggest that as the samples have adsorbed in high RH, they are unable to desorb the same quantity of water in low RH periods. This water has become 'trapped' and is retained within the sample, an efficient exchange of water molecules within the sample is integral for this panel to function as a $\mathrm{RH}$ regulator.

Despite this behaviour of 'trapping' water molecules, Figure 6 also demonstrates that all samples are still able to adsorb and desorb via clear increases in mass within 8 hours of adsorption and high RH (75\%) and then lose mass during 16 hours of desorption and low RH $(53 \%)$. Whilst the samples examined are still hygrothermally functional, the efficiency at which the water molecules are exchanged has reduced. Figure 6 shows that samples such as M1 SMR and M2 SMR are able to adsorb water at a much higher rate in comparison to the other samples. It is clear that M1 SMR has progressively increased in mass over the length of the experiment thus far, but, is able to return to the approximate same mass as at the beginning of the cycle. M2 W2 started to lose mass at the end of the cycle. This happens probably because water molecules 'trapped' within the sample are now dissolving the fibres and the sample is now beginning to decompose. 


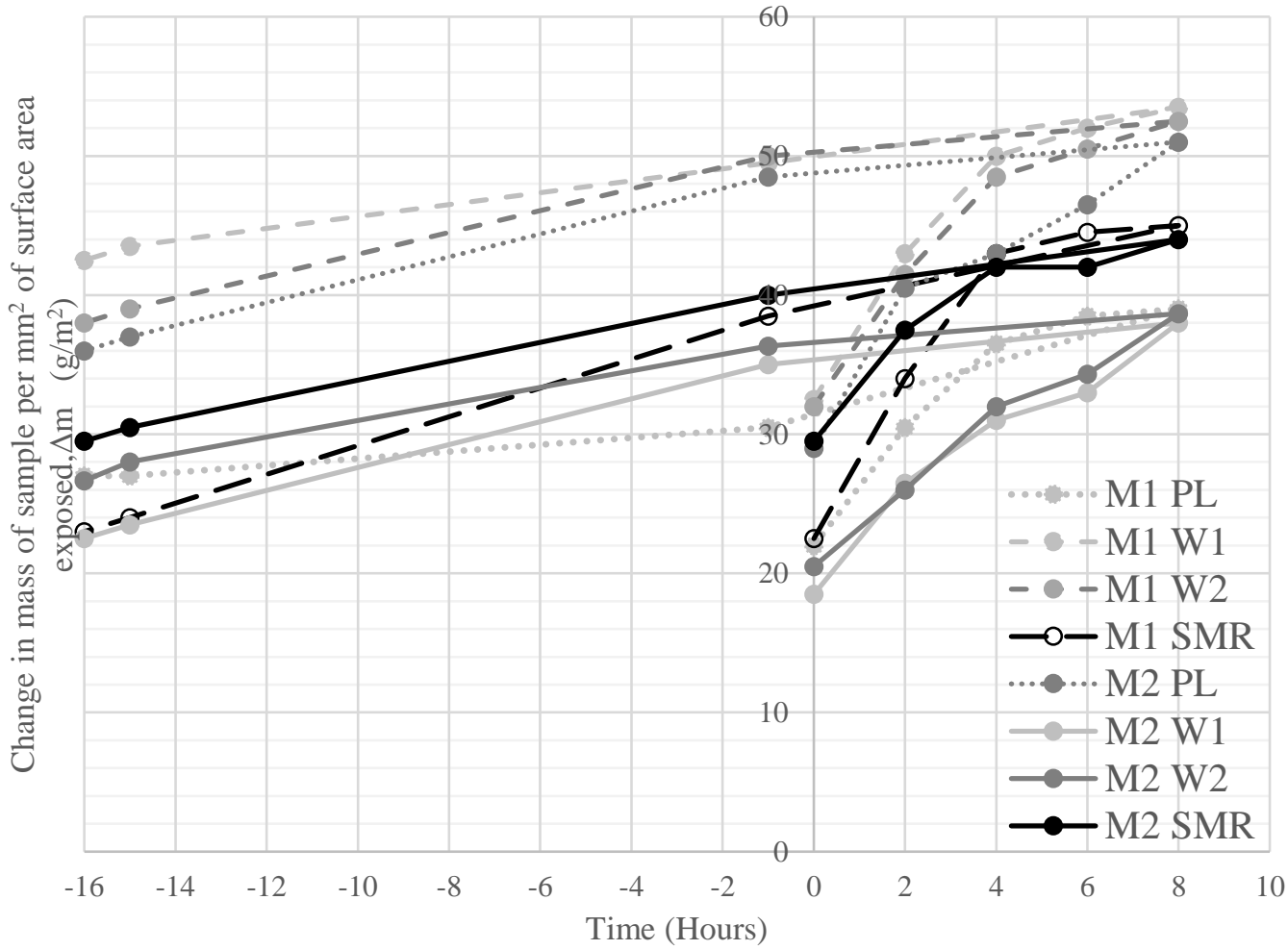

Figure 7. Adsorption/Desorption graph for all earth mortar samples after 15, 24 hour cycles.

Similar to Figure 6, Figure 7 demonstrates the vast range of the changes in mass throughout the $15^{\text {th }}$ cycle of 24 hours. When comparing M1 W1 and M1 W2 although they have an initial high adsorption levels, during the desorption phase the samples are not able to sufficient lose the water molecules they originally gained. Much like that of Figure 6, Figure 7 shows that M1 SMR has a clear high adsorption and is able to desorb to the approximate same mass as the start of the cycle. When comparing M1 PL and M2 PL, it is evident that both samples are able to initially adsorb but during desorption phase M1 PL is able to reduce to its original mass (but has a much lower original adsorption).

\section{CONCLUSION}

The paper demonstrates that the optimisation of both mix design and different bio-fibres will enable the next step towards the passive indoor RH regulating panel. Six different types of bio-composites with Saw Mill Residue (SMR), Wool 1 (WL1), Wool 2 (WL2) and a non-biofibre sample (PL) were tested. Capillary action shows that M1 has the lower capillary absorption by comparison to M2 for all mix designs within initial and plateau regions. M1 SMR has the most desirable features has it is able to remain hygrothermally effective after over 14, 24 hour cycles by comparison to the other mix designs. This mix design will be selected into other to further enhance the creation of the RH buffering panel.

\section{REFERENCES}

Asdrubali, F., D'Alessandro, F. and Schiavoni, S. (2015) A review of unconventional sustainable building insulation materials. Sustainable Materials and Technologies, 4, 1-17. 
RILEM's session 274-TCE: Testing and characterisation of earth-based building materials and elements

Aubert, J.E., Marcom, A., Oliva, P. and Segui, P. (2015) Chequered earth construction in south-western France. Journal of Cultural Heritage, 16 (3), 293-298.

Aymerich, F., Fenu, L. and Meloni, P. (2012) Effect of reinforcing wool fibres on fracture and energy absorption properties of an earthen material.

Bouguerra, A., Ledhem, A., de Barquin, F., Dheilly, R.M. and Quéneudec, M. (1998) Effect of microstructure on the mechanical and thermal properties of lightweight concrete prepared from clay, cement, and wood aggregates. Cement and Concrete Research, 28 (8), 1179-1190.

Cagnon, H., Aubert, J.E., Coutand, M. and Magniont, C. (2014) Hygrothermal properties of earth bricks. Energy \& Buildings, 80, 208-217.

CEN (1999a) BS EN 1015-1:1999 - Methods of test for mortar for masonry. Determination of particle size distribution (by sieve analysis).

CEN (1999b) BS EN 1015-2:1999 - Methods of test for mortar for masonry. Bulk sampling of mortars and preparation of test mortars.

CEN (1999c) BS EN 1015-3:1999 - Methods of test for mortar for masonry. Determination of consistence of fresh mortar (by flow table).

CEN (1999d) BS EN 1015-10:1999 - Methods of test for mortar for masonry. Determination of dry bulk density of hardened mortar.

CEN (2002) BS EN 1015-18:2002 - Methods of test for mortar for masonry. Determination of water absorption coefficient due to capillary action of hardened mortar.

CEN (2007) BS EN 1936:2006 - Natural stone test methods. Determination of real density and apparent density, and of total and open porosity.

Chabriac, P.-A., Morel, J.-C., Fabbri, A., J, B.-G. and Hans, S. (2013) A case study of the hygrothermal behaviour of rammed earth building.

Emiroğlu, M., Yalama, A. and Erdoğdu, Y. (2015) Performance of ready-mixed clay plasters produced with different clay/sand ratios. Applied Clay Science, 115, 221-229.

Gomes, M.I., Faria, P. and Gonçalves, T.D. (2018) Earth-based mortars for repair and protection of rammed earth walls. Stabilization with mineral binders and fibers. Journal of Cleaner Production, 172, 2401-2414. 
RILEM's session 274-TCE: Testing and characterisation of earth-based building materials and elements

ISO, I.O.f.S. (2008) Hygrothermal performance of building materials and products -

Determination of moisture adsorption/desoption properties in response to humidity. 24353.

Laborel-Préneron, A., Aubert, J.E., Magniont, C., Tribout, C. and Bertron, A. (2016) Plant aggregates and fibers in earth construction materials: A review. Construction and Building Materials, 111 (Supplement C), 719-734.

Lawrence, R.M., Mays, T.J., Rigby, S.P., Walker, P. and D'Ayala, D. (2007) Effects of carbonation on the pore structure of non-hydraulic lime mortars. Cement and Concrete Research, 37 (7), 1059-1069.

Lima, J., Faria, P. and Santos Silva, A. (2016) Earthen plasters based on illitic soils from Barrocal region of Algarve: contributions for building performance and sustainability.

Melià, P., Ruggieri, G., Sabbadini, S. and Dotelli, G. (2014) Environmental impacts of natural and conventional building materials: a case study on earth plasters. Journal of Cleaner Production, 80, 179-186.

Minke, G. (2006) Building with earth : design and technology of a sustainable architecture. Basel ; Boston: Basel ; Boston : Birkhauser-Publishers for Architecture.

Palumbo, M., Lacasta, A.M., Holcroft, N., Shea, A. and Walker, P. (2016) Determination of hygrothermal parameters of experimental and commercial bio-based insulation materials. Construction and Building Materials, 124 (Supplement C), 269-275.

Rode, C., Peuhkuri, R.H., Hansen, K.K., Time, B., Svennberg, K., Arfvidsson, J. and Ojanen, T. (2005) NORDTEST Project on Moisture Buffer Value of Materials. 47-52.

Romano, A., Brás, A., Grammatikos, S., Wylie, S., Kot, P. and Shaw, A. (2018) On the development of self-controlled bio-based panels for building's thermal management. European Conference on Composite Materials 